\title{
Treatment of whiplash-associated disorders - Part II: Medical and surgical interventions
}

\author{
Anne Conlin BA\&Sc, Sanjit Bhogal BA, Keith Sequeira MD FRCPC, Robert Teasell MD FRCPC
}

\begin{abstract}
A Conlin, S Bhogal, K Sequeira, R Teasell. Treatment of whiplash-associated disorders - Part II: Medical and surgical interventions. Pain Res Manage 2005;10(1):33-40.
\end{abstract}

BACKGROUND: Whiplash-associated disorder (WAD) is a term used to describe injury due to an acceleration-deceleration mechanism at the neck. In 1995, the Quebec Task Force published a report that contained evidence-based recommendations regarding the treatment of WAD based on studies completed before 1993 and consensusbased recommendations.

OBJECTIVE: The objective of the present article - the second installment of a two part review on WAD - is to provide a systematic review of the literature published between January 1993 and July 2003 on medical and surgical interventions for WAD using metaanalytical techniques.

METHODS OF THE REVIEW: Three medical literature databases were searched for identification of all clinical trials on the treatment of WAD. Randomized controlled trials (RCTs) and epidemiological studies were categorized by treatment modality and analyzed by outcome measures. The methodological quality of the RCTs was assessed. When possible, pooled analyses of the RCTs were completed for meta-analyses of the data. The results of all the studies were compiled and systematically reviewed.

RESULTS: The studies were categorized as medical or surgical interventions. A total of five RCTs and six non-RCTs were evaluated. The mean methodological quality of the RCTs was 7.3 among studies on medical interventions and 7.5 for studies on surgical intervention. Pooled analyses were completed across all treatment modalities and outcome measures. The outcomes of each study were summarized in tables.

CONCLUSIONS: While several quality RCTs and epidemiological studies have been published since 1993 on medical and surgical interventions, the cumulative evidence is lacking. Moderate evidence exists in support of radiofrequency neurotomy. Evidence for steroid injections, botulinum treatments, carpal tunnel decompression and cervical discectomy is conflicting or unclear. Future research is required to clarify the utility of radiofrequency neurotomy and pulsed electromagnetic field treatment for WAD.

Key Words: Medical intervention; Review; Surgical intervention; Whiplash-associated disorders

$\mathrm{T}$ he term 'whiplash' has been used to describe a mechanism of injury, the injury itself, a complex chronic pain syndrome, and a medicolegal and social dilemma. Treatment of whiplash has been similarly diverse, ranging from activationbased to medical to surgical interventions. In 1995, the

\section{Traitement des séquelles du syndrome du coup de fouet - Partie II : Interventions médicales et chirurgicales}

HISTORIQUE : Le syndrome du coup de fouet désigne la blessure consécutive à un phénomène mécanique d'accélération-décélération qui affecte le cou. En 1995, un groupe de travail québécois a publié un rapport qui contenait des recommandations au sujet du traitement du SCF fondées sur des preuves tirées d'études effectuées avant 1993, de même que des recommandations consensuelles.

OBJECTIF : L'objectif du présent article, le deuxième d'une série de deux sur le syndrome du coup de fouet, vise à faire une revue systématique de la littérature publiée entre janvier 1993 et juillet 2003 sur les interventions médicales et chirurgicales appliquées à ce type de problème par le biais de méta-analyses.

MÉTHODES D'ANALYSE : Trois bases de données de la littérature médicale ont été interrogées pour recenser tous les essais cliniques ayant porté sur le traitement du SCF. Les essais contrôlés randomisés (ECR) et les études épidémiologiques relevés ont été catégorisés par modalité thérapeutique et analysés selon les paramètres mesurés. La qualité méthodologique des essais randomisés et contrôlés a été évaluée. Dans la mesure du possible, des analyses regroupées de ces essais ont été effectués à des fins de méta-analyse des données. Les résultats de toutes les études ont été compilés et analysés de façon systématique.

RÉSULTATS : Les études ont été catégorisées selon qu'il s'agissait d'interventions chirurgicales ou médicales. En tout, six ERC et cinq essais d'autres types ont été évalués. La qualité méthodologique moyenne des ERC a été de 7,3 parmi les études portant sur les interventions médicales et de 7,5 parmi les études portant sur les interventions chirurgicales. Les analyses regroupées ont été complétées pour toutes les modalités thérapeutiques et les paramètres mesurés. Les conclusions de chaque étude ont été résumées dans des tableaux.

CONCLUSION : Bien que plusieurs ERC de qualité et études épidémiologiques aient été publiés depuis 1993 au sujet des interventions médicales et chirurgicales, les preuves accumulées sont lacunaires. On dispose de preuves de qualité modérée à l'appui de la neurotomie de radiofréquence. En ce qui a trait aux injections de corticostéroïdes et de toxine botulinique, à la décompression du tunnel carpien et à la discoïdectomie cervicale, les résultats sont divergents ou imprécis. Il faudra poursuivre la recherche pour clarifier l'utilité de la neurotomie de radiofréquence et le traitement par champ électromagnétique pulsé pour le syndrome du coup de fouet. 
scientific literature and expert opinions. However, the QTF concluded that the scientific evidence published before 1993 regarding whiplash was "sparse and generally of unacceptable quality" (1) and the QTF was left to rely on consensus opinions for the majority of its mandated treatment recommendations. Yet, in the years since the literature review by the QTF, many new scientific and nonscientific studies regarding whiplash-associated disorder (WAD) interventions have been published. The objective of this review is to identify and evaluate the literature on the treatment of acute and chronic whiplash injury that has been published since the completion of the literature review by the QTF in January 1993, and to provide recommendations for clinical practice and future research. In this second installment of a two-part series on treatment of WAD, medical and surgical interventions are reviewed.

\section{METHODS}

\section{Study identification and selection}

The MEDLINE and CINAHL databases and the Cochrane Central Register of Controlled Trials (CENTRAL) were searched for identification of studies published between 1993 and 2003 on the treatment and rehabilitation of WAD. The MEDLINE search key words included "whiplash injury" AND "therapy" OR "rehabilitation" OR "drug therapy" OR "radiotherapy", and the limits were English, human and subjects older than 18 years of age. The CINAHL search key words were "whiplash injury" AND "rehabilitation" OR "therapy" OR "diet therapy" OR "drug therapy" OR "surgery", with the limits of English and age greater than 18. The CENTRAL was searched using the term "whiplash injury", and the limits of English and age over 18 were applied.

Articles identified through the database searches were included in the present review if the purpose of the article was to study the effect of a specific, clearly defined treatment protocol on improvement of WAD secondary to motor vehicle collision. Randomized controlled trials (RCTs) and epidemiological studies, including cohorts, case-control studies and case series were included in this review. An RCT is an experiment in which subjects in a population are randomly allocated into groups to receive or not receive a therapeutic intervention; the subjects are prospectively studied to measure the outcome of interest. A cohort study is a nonrandomized epidemiological study that involves identifying two groups of subjects, one that receives the treatment and one that does not, and then following the groups to measure the outcome of interest. A case-control study is a retrospective epidemiological study which involves identifying subjects who have the outcome of interest (cases) and subjects without the same outcome (controls), and then reviewing the subjects to determine which ones had the treatment of interest. A case series is an epidemiological report on a series of patients with a treatment of interest. No control group is reported. Meta-analyses, reviews, abstracts, letters and case reports of single patients were read but excluded. Studies were not excluded on the basis of treatment protocol, outcome measure or quality assessment.

The MEDLINE search identified 88 articles, of which 20 met the inclusion criteria. Eighty-five articles were found through CINAHL, including six that were initially identified through the MEDLINE search. Four of the remaining articles met the inclusion criteria. The CENTRAL search yielded 43 articles, of which 11 were previously identified and two met the inclusion criteria. Finally, three studies that were cited in review articles and the included articles but not identified through the three databases were also retrieved, bringing the total number of clinical trials to 29 .

After all clinical trials on treatment of WAD were identified; three categories of interventions were developed: noninvasive interventions, medical interventions and surgical interventions. A total of 18 studies on noninvasive interventions were identified (see Part I of this review, pages 21-32). Four studies on medical interventions, three RCTs and one non-RCT, met the inclusion criteria. Seven publications on surgical interventions also met the inclusion criteria (two RCTs and five non-RCTs).

Included studies were selected for meta-analyses if four criteria were met. First, each study had to meet the definition of an RCT. Second, the studies had to assess the difference between a treatment and no treatment, a treatment and a placebo or sham treatment, or between two treatments. Dose-escalating studies were not included. Third, each study had to report the results of at least one common type of outcome measure for the calculation of a pooled effect size that incorporated the data from at least two studies. Fourth, duration of WAD injury was used to determine appropriate pooling of subject data for meta-analysis. Acute WAD was defined as any injury of less than three months duration, while chronic WAD was injury of more than three months. Studies that did not meet the inclusion criteria for meta-analysis were categorized, reviewed and summarized.

\section{Data abstraction}

The review process consisted of four parts: abstraction of data regarding methodology, outcome measures, results and final conclusions from each study; assessment of quality of the included RCTs; meta-analysis where inclusion criteria for meta-analysis were met; and summary of the findings and evidence in support of each treatment modality.

A single reviewer (AC) abstracted the data from each of the included RCTs using a predetermined data abstraction form. Information sought included sample population, subject inclusion and exclusion criteria, follow-up time period, and outcome measures. Outcome measures were categorized as pain measures, physical measures and function/coping measures. Pain measures included the Visual Analog Scale out of 10 or 100, the Pain Disability Index, the McGill Pain Questionnaire and subjective reports of pain. Physical measures included cervical range of motion (flexion, extension, left and right lateral flexion, and left and right rotation), kinesthetic sensibility, and head posture. Function/coping measures included the Self-Efficacy Score, the Vernon Mior Score, sick-leave profile, self-reported psychological distress and self-reported ability to complete activities of daily living.

Two independent evaluators ( $\mathrm{AC}$ and SB) evaluated the quality of the RCTs according to a standardized rating scale, the Physiotherapy Evidence Database (PEDro) scale, a validated tool used for the assessment of the quality of RCTs (2). The Physiotherapy Evidence Database scale (Table 1) consists of a list of 10 equally weighted criteria for quality assessment of RCTs. Raters were blinded to each other's results until all studies were assessed. Any discrepancies in the assessment of the articles were resolved by discussion between the reviewers until consensus was reached.

\section{Statistical analysis}

Among RCTs, results were analyzed to compare activationbased interventions with their control treatments. Data on the outcomes of each trial were pooled to arrive at an overall estimate of the effectiveness of the procedure. Analyses were based 
on the data provided at the end of the follow-up period. Subgroup analyses were used to determine the effects of each treatment modality on various outcomes of interest. For continuous data, including mean scores and mean change in scores, results were presented as weighted mean differences, where the difference between the treatment group and the control group was weighted by the inverse of the variance. For dichotomous outcomes, results were presented as an OR or RR. Fixed effects models were used where statistical homogeneity was demonstrated $(\mathrm{P}>0.05)$.

Evidence for and against all treatment protocols was summarized in tables. The summary tables identify treatments by category and duration of WAD injury. The findings of all RCTs within a given treatment category are reported. For treatment categories on which no RCTs have been published, the results of all reported epidemiological studies are summarized.

\section{RESULTS}

\section{Medically based intervention}

RCTs: The effectiveness of medically based interventions was assessed in three RCTs (Table 2). The mean methodological quality score of the included studies was seven, with a range from six to eight (Table 3 ).

Barnsley et al (3) measured the time from treatment to return to $50 \%$ of the pretreatment pain level in patients who received intra-articular injections of local anesthetic or corticosteroids, and found no significant difference between the groups. Pettersson and Toolanen (4) infused patients with methylprednisolone or its placebo equivalent and found significant difference between the treatment placebo groups on the outcome measures of disabling symptoms and sick-leave profile at six months follow-up. Finally, Freund and Schwartz (5) delivered botulinum toxin-A or saline to five trigger points in whiplash-injured patients. They reported that patients who received botulinum toxin-A had significantly improved pain and range of motion at four weeks post-treatment compared with pretreatment, but they failed to report any between-group comparisons.

Pooled analysis of RCTs: Of the RCTs categorized as medicalbased interventions, the studies by Pettersson and Toolanen (4) and Barnsley et al (3) were excluded on the basis of insufficient reporting of data. Freund and Schwartz (5) reported on both pain and range of motion, and the pooled analysis demonstrated no significant difference between the treatment and control groups $(\mathrm{P}=0.85$ and $\mathrm{P}=0.11$, respectively) (Figures 1 and 2). Similarly, there was no difference between treatment and control groups regarding the outcome measure of function $(\mathrm{P}=0.20)$ (Figure 3) (3).

Nonrandomized studies: One nonrandomized study assessed the effectiveness of medical intervention for treatment of WAD (Table 2). Slipman et al (6) followed 18 patients with whiplash injury of at least three months duration after therapeutic steroids and analgesis (Celestone Soluspan, Shering, Canada, and Xylocaine, AstraZeneca, Canada) were given by intraarticular injection to the C2-C3 joint. Improvement was seen in the outcome measures of headache frequency, medication usage, symptom response and employment status; however, statistical significance was not reported.

Levels of evidence: Overall, four studies assessed medicalbased interventions for WAD. Table 4 provides a summary of the results of these studies by treatment modality and WAD duration.

\section{TABLE 1}

The Physiotherapy Evidence Database criteria

\begin{tabular}{|c|c|c|}
\hline & Subjects were randomly allocated to groups & No/Yes \\
\hline 2. & Allocation was concealed & No/Yes \\
\hline 3. & $\begin{array}{l}\text { The groups were similar at baseline regarding the most } \\
\text { important prognostic indicators }\end{array}$ & No/Yes \\
\hline 4. & There was blinding of all subjects & No/Yes \\
\hline 5. & $\begin{array}{l}\text { There was blinding of all therapists who administered } \\
\text { the therapy }\end{array}$ & No/Yes \\
\hline 6. & $\begin{array}{l}\text { There was blinding of all assessors who measured at } \\
\text { least one key outcome }\end{array}$ & No/Yes \\
\hline 7. & $\begin{array}{l}\text { Measures of at least one key outcome were obtained } \\
\text { from more than } 85 \% \text { of the subjects initially allocated } \\
\text { to groups }\end{array}$ & No/Yes \\
\hline 8. & $\begin{array}{l}\text { All subjects for whom outcome measures were available } \\
\text { received the treatment or control condition as allocated or, } \\
\text { where this was not the case, data for at least one key } \\
\text { outcome were analyzed by 'intention to treat' }\end{array}$ & No/Yes \\
\hline 9. & $\begin{array}{l}\text { The results of between-group statistical comparisons are } \\
\text { reported for at least one key outcome }\end{array}$ & No/Yes \\
\hline & $\begin{array}{l}\text { The study provides both point measures and measures } \\
\text { of variability for at least one key outcome }\end{array}$ & No/Yes \\
\hline
\end{tabular}

Data from reference 2

\section{Surgically based intervention}

RCTs: Two RCTs were categorized as surgically based interventions (Table 5). The methodological scores of the studies were high, at seven and eight out of 10 (Table 6). Radiofrequency neurotomy provided relief of pain and psychological distress for the majority of patients who received it; however, no statistical comparison was made between treatment and control groups (7). In another study, significantly longer periods of time elapsed before pain returned to $50 \%$ pretreatment levels among patients who underwent radiofrequency neurotomy compared with controls $(\mathrm{P}=0.04)(8)$.

Pooled analysis of RCTs: Pooled analysis was considered for both studies on radiofrequency neurotomy $(7,8)$. Sufficient data was reported for only the outcome measure of complete relief of pain. Pooled analysis across 21 patients indicated that radiofrequency neurotomy was favoured over control treatment for relief of pain (OR 6.74; 95\% CI 1.57 to 28.97) (Figure 4). Nonrandomized studies: Five nonrandomized studies assessed the effectiveness of surgical-based intervention for treatment of patients with chronic WAD (Table 5). Alpar et al (9) compared 38 patients suffering from WAD with neck, shoulder and arm symptoms who underwent surgical decompression of the carpal tunnel to 30 patients with similar symptoms and no surgery. The researchers reported only the proportion of patients who improved and found that at a mean follow-up time of 18 months, neck and shoulder pain resolved in $95 \%$ of surgery patients but only in 7\% of controls.

Sapir and Gorup (10) followed 46 patients with whiplash injury of at least 20 weeks who underwent therapeutic radiofrequency cervical medial neurotomy. Significant reduction in pain and self-reported whiplash symptoms were found initially and one year after the surgery. McDonald et al (11) similarly performed therapeutic percutaneous radiofrequency neurotomy at C3-C4 and C6-C7 on 28 patients with WAD of one year or more. While significance was not reported, the researchers demonstrated that $71 \%$ of patients had complete relief of pain for at least 90 days and the median duration of relief was 
TABLE 2

Summary of medically based intervention studies

\begin{tabular}{|c|c|c|c|}
\hline $\begin{array}{l}\text { Authors, } \\
\text { year, country }\end{array}$ & Population and methods & Outcome measures & Results \\
\hline $\begin{array}{l}\text { Barnsley et al, } \\
\text { 1994, Australia (3) }\end{array}$ & $\begin{array}{l}\text { Randomized controlled trial - Forty-one } \\
\text { patients with pain in one or more cervical } \\
\text { zygapophyseal joint due to whiplash injury of } \\
\text { greater than } 3 \text { months duration were randomly } \\
\text { assigned to receive } 1 \mathrm{~mL} \text { intra-articular injection } \\
\text { of bupivacaine }(0.5 \%) \text { or betamethasone } \\
\text { (5.7 mg). Patients were followed by regular } \\
\text { telephone contact and clinic visits at } 2 \text { weeks }\end{array}$ & Time from treatment to $50 \%$ return of pain. & $\begin{array}{l}\text { There was no significant difference in } \\
\text { the duration of pain relief between } \\
\text { the corticosteroid and local } \\
\text { anesthetic groups. Median time for } \\
\text { a return to } 50 \% \text { of the preinjection } \\
\text { level of pain was } 3 \text { days in the } \\
\text { steroid group and } 3.5 \text { days in the } \\
\text { local anesthetic group }(P=0.42) \text {. }\end{array}$ \\
\hline
\end{tabular}

Pettersson and Toolanen, 1998, Sweden (4)
Freund and Schwartz, 2000, Canada (5)
Slipman et al, 2001, United States (6) to $50 \%$ of preinjection pain level.

\section{Randomized controlled trial - Forty patients} with acute whiplash injury who were treated within $8 \mathrm{~h}$ were randomized to 2 groups:

20 patients were infused with methyprednisolone (bolus at $30 \mathrm{mg} / \mathrm{kg} / \mathrm{h}$ for $15 \mathrm{~min}$ and maintenance at $5.4 \mathrm{mg} / \mathrm{kg} / \mathrm{h}$ for $23 \mathrm{~h}$ ) and 20 patients received its placebo equivalent. All patients also had cointervention, including soft collar use for 1-2 weeks, physiotherapy and analgesics; no other modalities were used.

Randomized controlled trial - Twenty-six patients with whiplash injury of at least 6 months and refractory to conservative treatment were divided into two groups: 14 received 100 units of botulinum toxin- $A$ diluted in saline and 12 received $1 \mathrm{~mL}$ saline delivered to five trigger points

Case series - Eighteen patients with whiplashassociated disorders and chronic daily headaches refractive to at least 3 months of physiotherapy, activity restriction and oral analgesics were included. Patient received intra-articular C2-C3 joint injections of Xylocaine (AstraZeneca, Canada) for diagnosis and Celestone Soluspan (Shering, Canada) plus Xylocaine for treatment.
Presence of disabling symptoms severe enough to prevent the patient from returning to work, number of sick days in the 6 month period before and after the injury, and sick-leave profile after injury were evaluated at 6 months.
There was a significant difference between the actively treated patients and the placebo group in disabling symptoms $(P=0.047)$, the total number of sick days $(P=0.01)$ and the sick-leave profile $(P=0.003)$.
Neck, head and shoulder pain, range of motion and function were assessed initially and at 2 weeks and 4 weeks post-treatment.

Headache frequency, medication usage, symptom response to medication and employment status measured at an average of 19 months after treatment.
No between-group comparisons were reported. At 4 weeks post-treatment, the botulinum group had significantly improved from pretreatment on pain and range of motion.
All patients demonstrated a positive response to diagnostic intra-articular injection. Improvements were seen across all outcome measures, but statistical significance was not reported.

\section{TABLE 3}

The Physiotherapy Evidence Database (PEDro) quality assessment scores for randomized controlled trials on medical interventions

\begin{tabular}{|c|c|c|c|c|c|c|c|c|c|}
\hline \multirow[b]{2}{*}{ Authors, year } & \multicolumn{9}{|c|}{ PEDro criteria } \\
\hline & RA & CA & BS & SB & TB & $A B$ & OM ITT & BC PVM & Total \\
\hline $\begin{array}{l}\text { Pettersson and } \\
\text { Toolanen, } 1998 \text { (4) }\end{array}$ & $\sqrt{ }$ & $\sqrt{ }$ & $\sqrt{ }$ & $\sqrt{ }$ & $\sqrt{ }$ & $\sqrt{ }$ & $\sqrt{ }$ & $\sqrt{ }$ & 8 \\
\hline $\begin{array}{l}\text { Barnsley et al, } \\
1994 \text { (3) }\end{array}$ & $\sqrt{ }$ & & $\sqrt{ }$ & $\sqrt{ }$ & $\sqrt{ }$ & $\sqrt{ }$ & $\sqrt{ }$ & $\sqrt{ }$ & 7 \\
\hline $\begin{array}{l}\text { Freund and } \\
\text { Schwartz, } 2000 \text { (5) }\end{array}$ & $\sqrt{ }$ & & $\sqrt{ }$ & $\sqrt{ }$ & & $\sqrt{ }$ & $\sqrt{ }$ & $\sqrt{ }$ & 7 \\
\hline
\end{tabular}

AB Assessor blinding; BC Between-group comparison; BS Baseline similarity of subjects; CA Concealed allocation; ITT Intention-to-treat analysis; OM Outcomes measures of $85 \%$ of subjects or more; PVM Point and variability measures; RA Random allocation; SB Subject blinding; TB Therapist blinding
TABLE 4

Summary of evidence for medically based interventions

\begin{tabular}{|c|c|c|}
\hline Intervention & Duration of WAD & Summary of evidence \\
\hline Steroid injections & $\begin{array}{l}\text { Acute and chronic } \\
\text { WAD }\end{array}$ & $\begin{array}{l}\text { Conflicting findings in two } \\
\text { RCTs regarding pain }\end{array}$ \\
\hline Botulinum treatments & Chronic WAD & $\begin{array}{l}\text { One RCT reported } \\
\text { improvement in pain and } \\
\text { range of motion but did not } \\
\text { provide statistical } \\
\text { comparison }\end{array}$ \\
\hline
\end{tabular}

RCT Randomized controlled trial; WAD Whiplash-associated disorder 


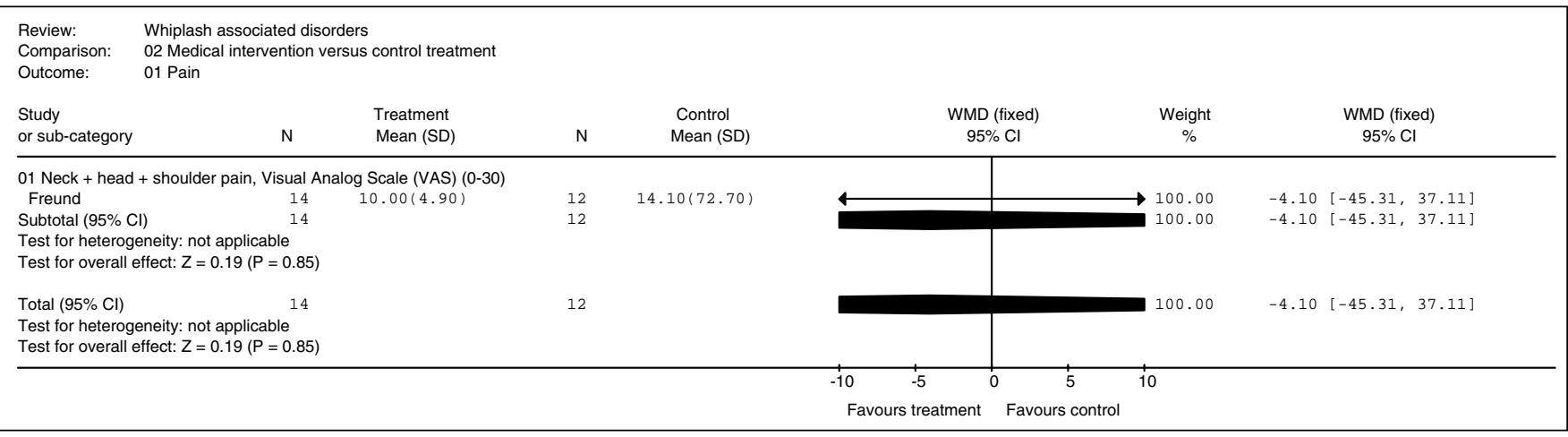

Figure 1) Medical intervention versus control treatment: degree of pain. WMD Weighted mean difference

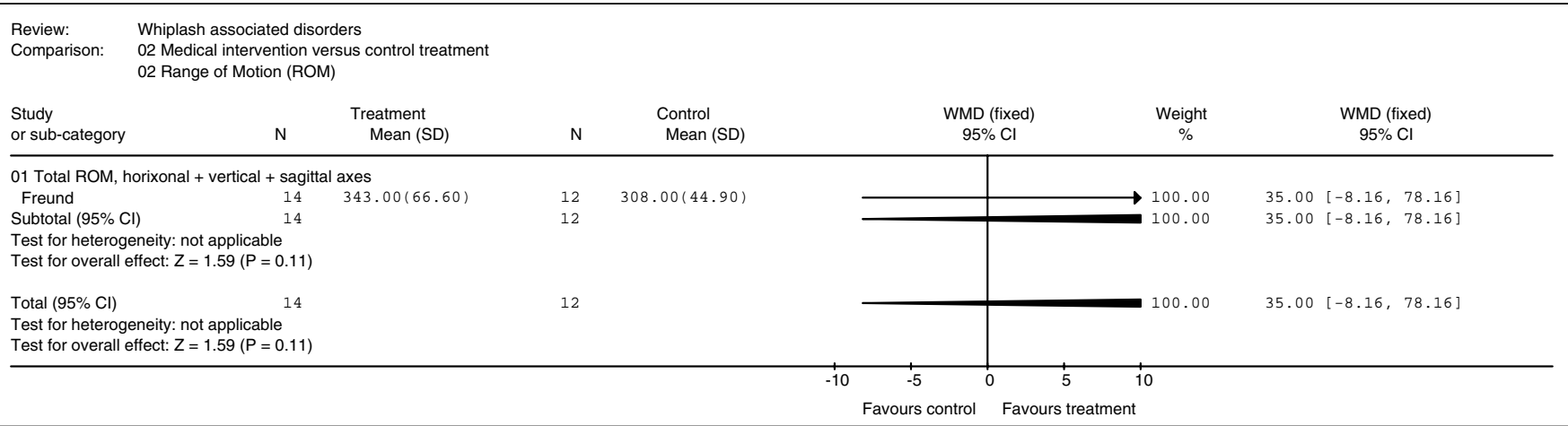

Figure 2) Medical intervention versus control treatment: range of motion. WMD Weighted mean difference

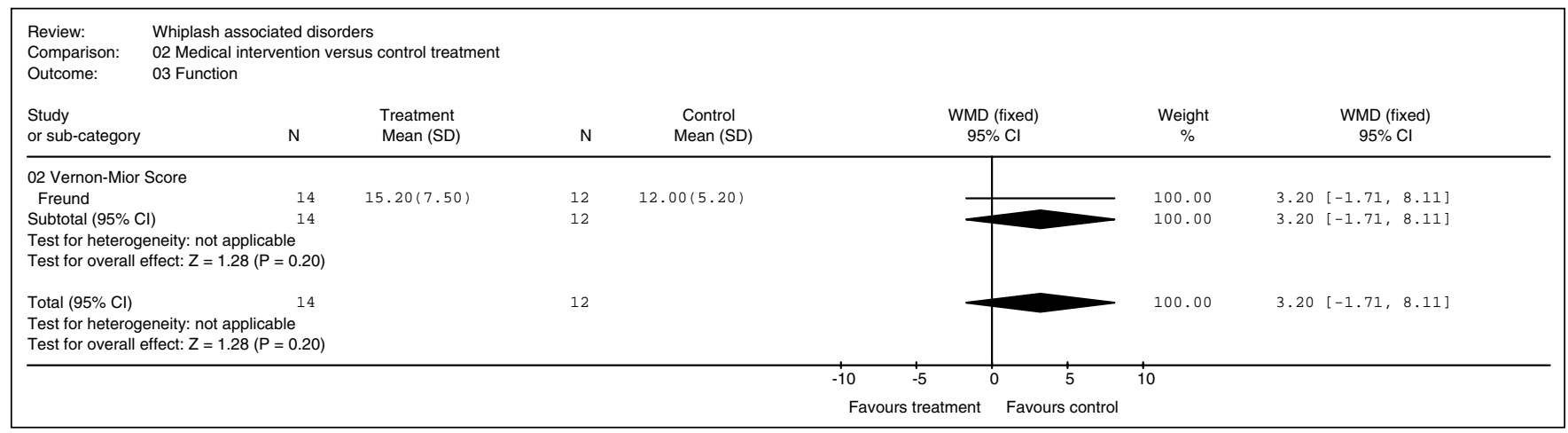

Figure 3) Medical intervention versus control treatment: function. WMD Weighted mean difference

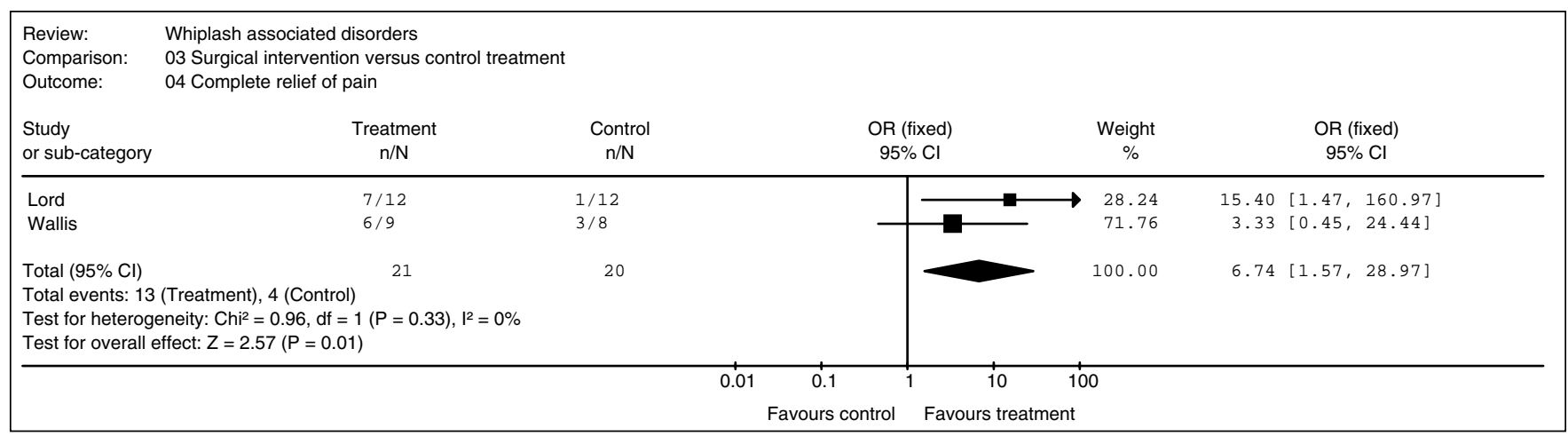

Figure 4) Surgical intervention versus control treatment: complete relief of pain. WMD Weighted mean difference 


\section{Conlin et al}

\section{TABLE 5}

Summary of surgically based interventions

\begin{tabular}{|c|c|}
\hline $\begin{array}{l}\text { Authors, } \\
\text { year, country }\end{array}$ & Population and methods \\
\hline $\begin{array}{c}\text { Lord et al, } 1996, \\
\text { Australia (8) }\end{array}$ & $\begin{array}{l}\text { Randomized controlled trial - Twenty-four patients } \\
\text { with pain in one or more cervical zygapophysial } \\
\text { joints (excluding C2-C3) for greater than } 3 \text { months } \\
\text { after whiplash injury and failed conventional therapy } \\
\text { were randomized to two groups. Twelve patients } \\
\text { were assigned to percutaneous radiofrequency } \\
\text { neurotomy treatment and } 12 \text { to sham neurotomy } \\
\text { treatment. }\end{array}$ \\
\hline
\end{tabular}

Wallis et al

Randomized controlled trial - Seventeen patients

1997, Australia

(7)

Algers et al, 1993, Sweden

(13)

Lord et al, 1995 Australia (12)

McDonald et al, 1999, Australia (11)

Sapir and Gorup, Case series - Forty-six patients with cervical 2001, United States (10) 2002, England
Case series - Twenty patients with symptoms of prolonged headache, neck pain and radicular pain for an average of 7 years after whiplash injury underwent anterior cervical discectomy with interbody fusion.

Case series - Nineteen patients referred with at were diagnosed through local anesthetic and placebo-controlled cervical zygapophysial joint blocks. Ten patients underwent therapeutic third occipital neurotomy and 10 underwent lower cervical medial branch neurotomy. A total of 28 procedures were performed for treatment of 21 joints

Case series - Twenty-eight patients with neck pain of more than 12 months duration underwent diagnostic local anesthetic and placebo-controlled cervical zygapophysial joint blocks and therapeutic percutaneous radiofrequency neurotomy between C3-C4 and C6-C7. The procedure was repeated in patients whose pain recurred. least 3 months of whiplash-associated neck pain

Four years after the surgery, patients were assessed for pain and symptoms.

Duration of complete pain relief. Progress was recorded at 3 and 12 months follow-up or when the pain returned.

Proportion of patients who responded to the initial procedure and the duration of relief obtained.

Pain and self-report of improvement were obtained before, immediately after, and 1 year after treatment. earlier were referred to one centre following failed conservative treatment. 28 patients were litigant and 18 patients were nonlitigant. All patients underwent diagnostic cervical medial branch block and therapeutic radiofrequency cervical medial neurotomy.

Cohort - Thirty-eight patients with chronic neck, shoulder and arm pain attributed to whiplash injury and refractive to physiotherapy, nonsteroidal anti-inflammatory drugs and collar use for 1 to 3 weeks were treated by surgical decompression of the carpal tunnel. Thirty patients with similar signs and symptoms served as controls.

After one year of conservative treatment, the subjects were assessed for pain. Mean follow-up time was 18 months (range 12 to 24 months).
Results

Six of 12 control group patients and 3 of

12 active treatment patients had return of pain immediately after the operation. Significantly different median times elapsed before pain returned to $50 \%$ preoperative level: 263 days in the active treatment group and 8 days in the sham treatment group $(P=0.04)$.

Six of 9 patients with active treatment had complete relief of pain and 7 of 9 had complete relief of psychological distress. Three of 8 patients with the placebo procedure had pain relief and resolution of their psychological distress. No between group statistics were reported.

Eleven patients had reduced headache and neck pain, 6 patients had reduced paresthesia, and 3 patients had reduced radicular pain. No patients had improved vertigo or visual and auditory symptoms.

Three of 10 patients who underwent third occipital nerve neurotomy obtained longlasting relief for clinically useful periods (6 months to 2 years). Seven of the 10 patients who underwent lower cervical medial branch neurotomy achieved complete relief for clinically useful periods and were able to return to work and resume their activities of daily living.

Complete relief of pain for at least 90 days was obtained in $71 \%$ of patients after one or more attempts at operation. Pain refractory to the initial treatment did not respond to a second treatment, but recurrent pain that was relieved by the initial treatment was also relieved by a second treatment. The median duration of relief after the first procedure was 219 days across all cases and 422 for only successful cases.

Reduction in whiplash symptoms and pain were significant $(\mathrm{P}<0.005)$ immediately after treatment and at 1 year in each group. The difference between litigants and nonlitigants in symptoms or response to treatment did not reach significance.
Neck and shoulder pain resolved in 36 but only in 2 patients $(7 \%)$ of the contro group. patients (95\%) who underwent surgery 


\section{TABLE 6}

The Physiotherapy Evidence Database (PEDro) quality assessment scores for randomized controlled trials on surgical interventions

\begin{tabular}{|c|c|c|c|c|c|c|c|c|c|c|c|}
\hline \multirow[b]{2}{*}{ Authors, year } & \multicolumn{11}{|c|}{ PEDro criteria } \\
\hline & RA & $\mathrm{CA}$ & BS & SB & TB & $A B$ & OM & ITT & $\mathrm{BC}$ & PVM & Total \\
\hline Lord et al, 1996 (8) & $\sqrt{ }$ & $\sqrt{ }$ & $\sqrt{ }$ & $\sqrt{ }$ & $\sqrt{ }$ & $\sqrt{ }$ & $\sqrt{ }$ & & $\sqrt{ }$ & & 8 \\
\hline Wallis et al, 1997 (7 & $\sqrt{ }$ & & $\sqrt{ }$ & $\sqrt{ }$ & $\sqrt{ }$ & $\sqrt{ }$ & & & $\sqrt{ }$ & $\sqrt{ }$ & 7 \\
\hline
\end{tabular}

AB Assessor blinding; BC Between-group comparison; BS Baseline similarity of subjects; CA Concealed allocation; ITT Intention-to-treat analysis; OM Outcomes measures of $85 \%$ of subjects or more; PVM Point and variability measures; RA Random allocation; SB Subject blinding; TB Therapist blinding

219 days. Lord et al (12) conducted a nonrandomized study to assess the effectiveness of third occipital neurotomy and lower cervical medial branch neurotomy on patients with a history of whiplash injury of three months or greater. Statistical significance was not reported, but the researchers did report that $30 \%$ of patients who underwent third occipital neurotomy and $70 \%$ of patients who underwent lower cervical medial branch neurotomy achieved complete relief of pain for at least six months. Lastly, Algers et al (13) treated 20 patients with WAD for an average of seven years with anterior cervical discectomy and interbody fusion. Four years after surgery, 11 of 20 patients had reduced headache and neck pain, six had reduced paresthesia, and three had reduced radicular pain; however, statistical significance was not reported.

\section{Levels of evidence}

The evidence provided by the seven studies designed to assess the efficacy of surgical-based interventions is summarized in Table 7 by treatment modality and duration of WAD.

\section{DISCUSSION}

In 1995, the QTF, a panel of expert clinicians and epidemiologists, was commissioned to make public policy recommendations on the prevention and treatment of whiplash-associated disorders (1). The stated reasons for commissioning the study reflected concerns with both the magnitude of the problem of WAD and the paucity of evidence-based interventions to effectively manage it. However, the majority of the studies evaluated by the QTF were based on nonmedical and nonsurgical interventions, and the QTF recommended that medical and surgical treatments of WAD be areas of future research. Since 1993, multiple RCTs and non-RCTs have been published to address this.

Recommendations for clinical practice cannot be made regarding medically based interventions. Discrepant findings were reported in two RCTs, providing conflicting evidence regarding the utility of steroid injections for the treatment of pain in patients with acute and chronic WAD. As well, the methodological limitations of the single RCT on botulinum toxin treatments for WAD provides unclear evidence regarding its effectiveness. However, given the positive findings suggested by some studies, further research is warranted to more conclusively identify the role of these less-invasive interventions for clinical practice.

Studies regarding surgical interventions, however, have provided more promising results. First, beneficial outcomes from two RCTs exist to support radiofrequency neurotomy as an effective intervention for patients with chronic WAD.
TABLE 7

Levels evidence for surgically based interventions

\begin{tabular}{|c|c|c|}
\hline Intervention & $\begin{array}{l}\text { Duration } \\
\text { of WAD }\end{array}$ & Summary of evidence \\
\hline $\begin{array}{l}\text { Radiofrequency } \\
\text { neurotomy }\end{array}$ & Chronic & $\begin{array}{l}\text { Two RCTs reported improvement in } \\
\text { pain and psychological distress }\end{array}$ \\
\hline $\begin{array}{l}\text { Carpal tunnel } \\
\text { decompression }\end{array}$ & Chronic & $\begin{array}{l}\text { One non-RCT supported this treatment } \\
\text { for pain relief but failed to report } \\
\text { between-group statistics. }\end{array}$ \\
\hline $\begin{array}{l}\text { Cervical } \\
\text { discectomy }\end{array}$ & Chronic & $\begin{array}{l}\text { One non-RCT found pain relief but did } \\
\text { not provide a control group } \\
\text { comparison }\end{array}$ \\
\hline
\end{tabular}

RCT Randomized controlled trial; WAD Whiplash-associated disorder

By the methods of this review, radiofrequency neurotomy would be deemed an intervention with "strong" supportive evidence. However, on close comparison of the patient characteristics and the methodologies in the two studies, it appears that the same patients were used in each RCT. Consequently, one must exercise caution when compiling the evidence for radiofrequency neurotomy. It appears that there is in fact only moderate evidence from essentially one RCT to support the efficacy of radiofrequency neurotomy for improvement in pain and psychological distress among chronically injured patients with WAD. Finally, interesting non-RCTs have been published on carpal tunnel decompression and cervical discectomy in WAD patients. Unfortunately, both studies failed to report between-group statistics, and as such, the results are unclear and recommendations regarding the utility of these interventions for clinical practice cannot be made.

In the 10 years since the completion of the literature review by the QTF, remarkably little quality research has been published on interventions for patients with WAD, despite the QTF's recommendations. Whiplash-associated disorders, however, continue to represent an astounding social and economic cost, totalling up to $\$ 29$ billion annually in the United States $(14,15)$. Moreover, whiplash is a particularly common injury, afflicting four persons per 1000 people per year (16). At present, large, well-designed RCTs are needed to further substantiate the positive findings of the studies published on intra-articular injections, radiofrequency neurotomy and pulsed magnetic field treatment. As the understanding of the effectiveness of these interventions unfolds, future research directed at patient subpopulations might provide greater insight into the utility of specific interventions for both acutely and chronically injured whiplash patients.

\section{REFERENCES}

1. Spitzer WO, Skovron ML, Salmi LR, et al. Scientific monograph of the Quebec Task Force on Whiplash-Associated Disorders:

Redefining "whiplash" and its management. Spine 1995;20:2S-73.

2. Maher CG, Sherrington C, Herbert RD, Moseley AM, Elkins M. Reliability of the PEDro scale for rating quality of randomized controlled trials. Phys Ther 2003;83:713-21.

3. Barnsley L, Lord SM, Wallis BJ, Bogduk N. Lack of effect of intraarticular corticosteroids for chronic pain in the cervical zygapophyseal joints. N Engl J Med 1994;330:1047-50.

4. Pettersson K, Toolanen G. High-dose methylprednisolone prevents extensive sick leave after whiplash injury. Spine 1998;23:984-9.

5. Freund BJ, Schwartz M. Treatment of whiplash associated neck pain with botulinum toxin-A: A pilot study. J Rheumatol

2000;27:481-4. 


\section{Conlin et al}

6. Slipman CW, Lipetz JS, Plastaras CT, Jackson HB, Yand ST, Meyer AM. Therapeutic zygapophyseal joint injections for headaches emanating from the C2-3 joint. Am J Phys Med Rehabil 2001;80:182-8

7. Wallis BJ, Lord SM, Bogduk N. Resolution of psychological distress of whiplash patients following treatment by radiofrequency neurotomy: A randomised, double-blind, placebo-controlled trial. Pain 1997;73:15-22.

8. Lord SM, Barnsley L, Wallis BJ, McDonald GJ, Bogduk N. Percutaneous radio-frequency neurotomy for chronic cervical zygapophyseal-joint pain. N Engl J Med 1996;335:1721-6.

9. Alpar EK, Onuoha G, Killampalli VV, Waters R. Management of chronic pain in whiplash injury. J Bone Joint Surg Br 2002;84:807-11.

10. Sapir DA, Gorup JM. Radiofrequency medial branch neurotomy in litigant and nonlitigant patients with cervical whiplash. Spine 2001;26:E268-73.
11. McDonald GJ, Lord SM, Bogduk N. Long-term follow-up of patients treated with cervical radiofrequency neurotomy for chronic neck pain. Neurosurgery 1999;45:61-8.

12. Lord SM, Barnsley L, Bogduk N. Percutaneous radiofrequency neurotomy in the treatment of cervical zygapophysial joint pain A caution. Neurosurgery 1995;36:732-9.

13. Algers G, Pettersson K, Hildingsson C, Toolanen G. Surgery for chronic symptoms after whiplash injury. Acta Orthop Scand 1993;64:654-6.

14. Lord SM, Barnsley L, Wallis BJ, Bogduk N. Chroinc cervical zygapophysial joint pain after whiplash: A placebo-controlled prevalence study. Spine 1996;21:1737-44.

15. Freeman MD, Croft AC, Rossignol AM, Weaver DS, Reiser M. A review and methodologic critique of the literature refuting whiplash syndrome. Spine 1999;24:86-96.

16. Lovell ME, Galasko CS. Whiplash disorders: A review. Injury 2002;33:97-101 


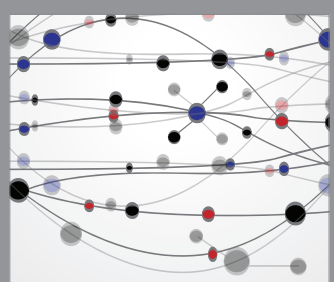

The Scientific World Journal
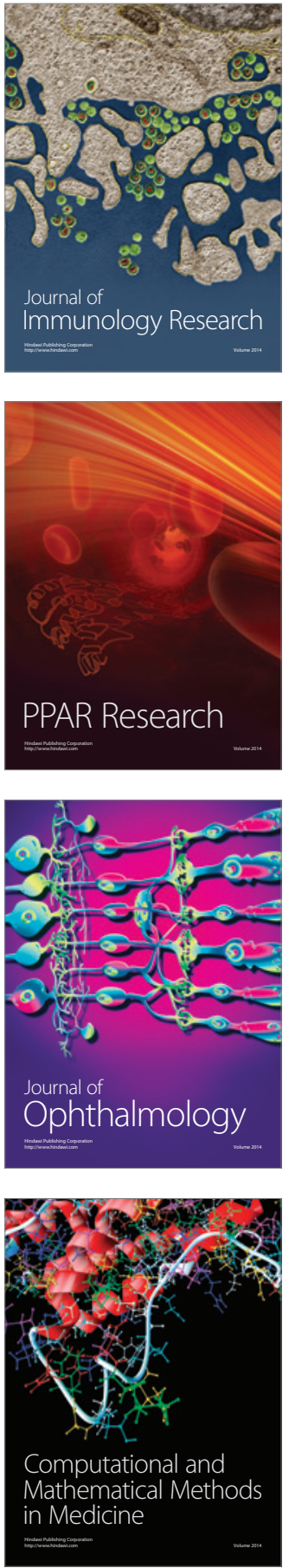

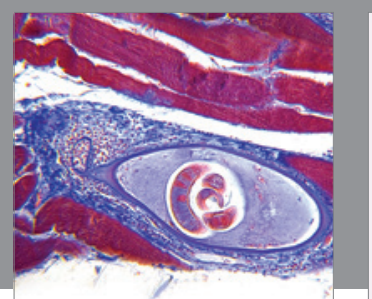

Gastroenterology Research and Practice

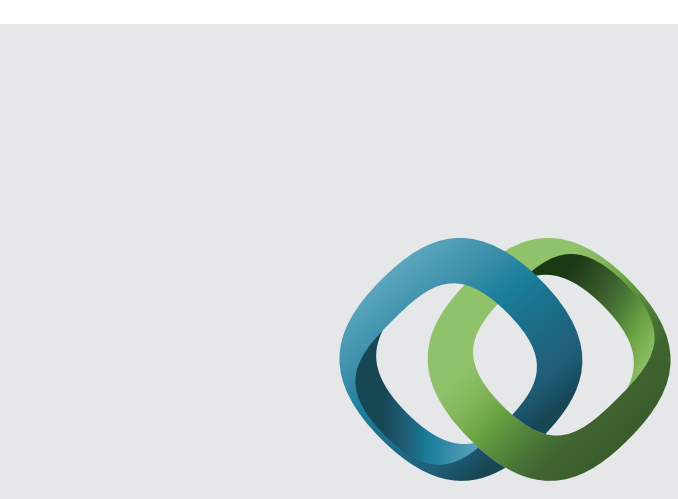

\section{Hindawi}

Submit your manuscripts at

http://www.hindawi.com
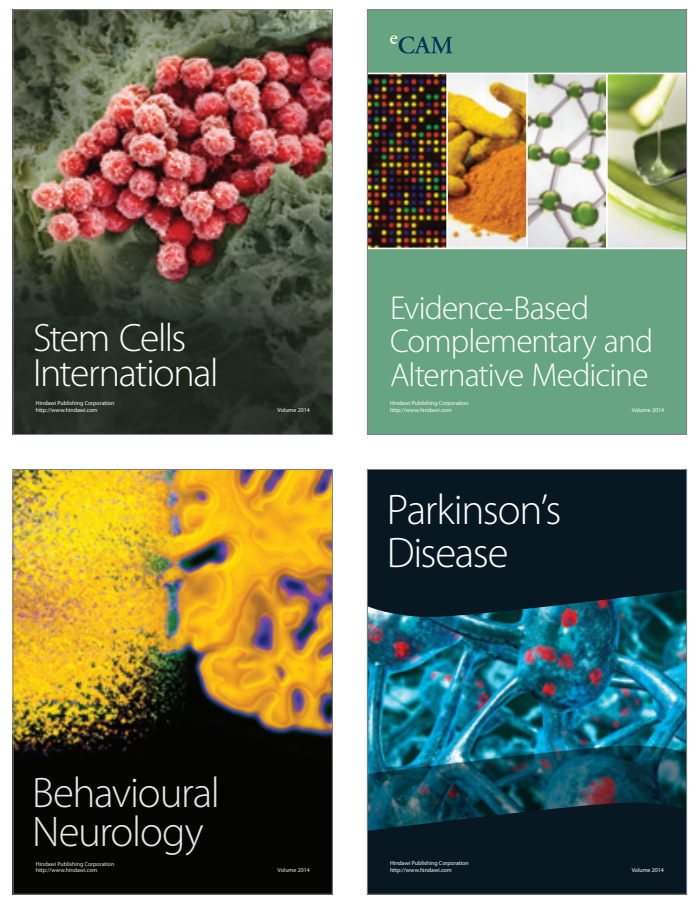
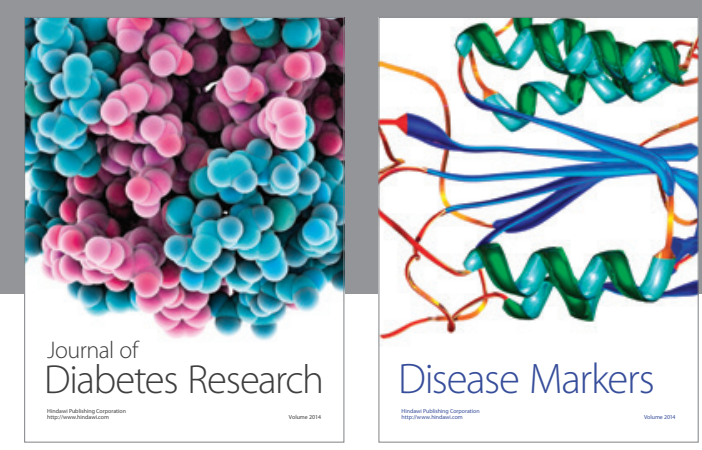

Disease Markers
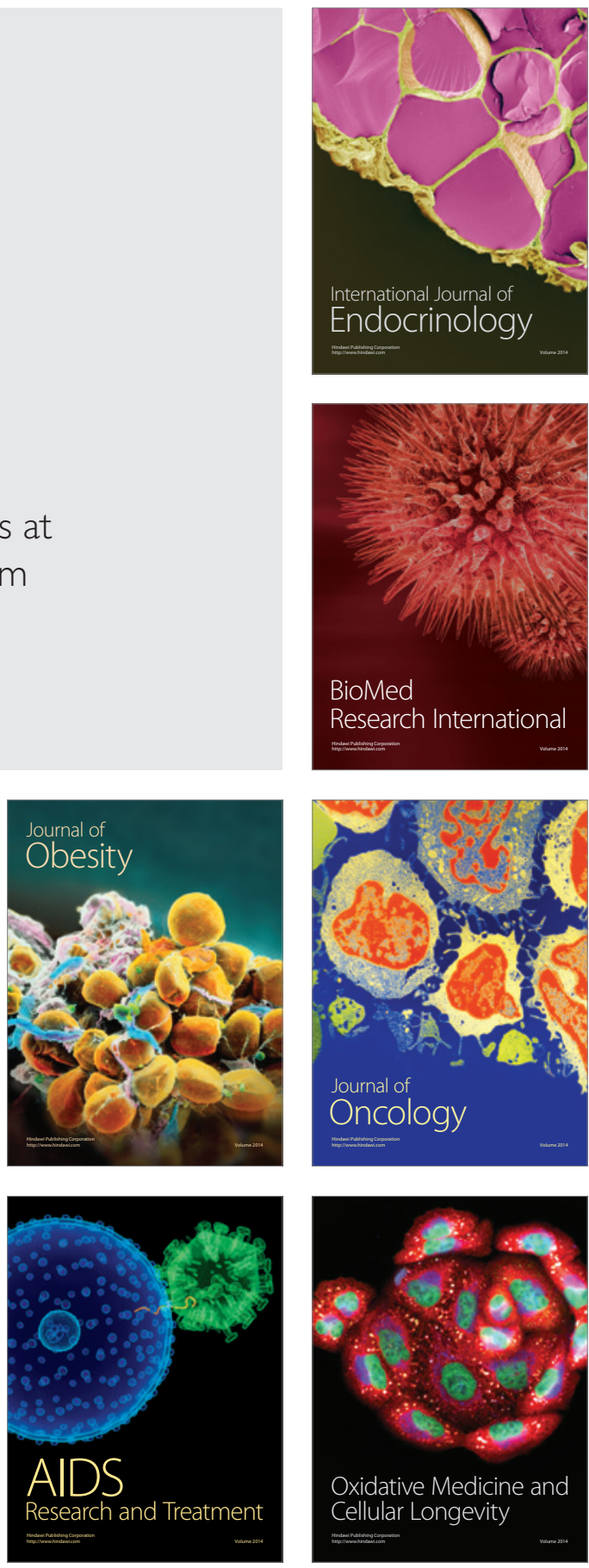